\title{
CiênCia E ética em Popper: a ética da REsPonsabilidade DOS CIENTISTAS
}

Elizabeth de Assis Dias ${ }^{1}$

\begin{abstract}
Resumo: O presente trabalho tem por objetivo analisar as relaçôes entre ciência e ética em Popper, mais precisamente, a natureza dessa ética que está na base de sua teoria da ciência. A pretensão é evidenciar que sua concepçáo de ciência está alicerçada em uma ética da responsabilidade, a qual pressupốe a autonomia dos cientistas, sua liberdade de escolha, o que os torna responsáveis por suas decisôes por determinados "padrôes" de pesquisa. Almeja-se mostrar que essa ética da responsabilidade já se faz presente em sua lógica da investigação, de forma pouco explícita, quando suas preocupaçóes estão voltadas para o problema da demarcação científica e sua proposta de um critério de cientificidade e de uma metodologia para a ciência. A adoção de tal proposta requer dos cientistas uma decisão que envolve objetivos e valores. Em escritos, nos quais expressa suas preocupaçóes com questôes éticas inerentes a ciência, essa ética da responsabilidade se apresenta de forma nítida, ao definir certos compromissos para os cientistas, tendo por base o juramento de Hipócrates, bem como os princípios éticos que devem nortear suas pesquisas.
\end{abstract}

Palavras-chave: Ciência. Ética. Valores. Autonomia. Responsabilidade.

\section{INTRODUÇÁO}

Popper ocupa um lugar de destaque na filosofia da ciência e na filosofia política do século XX. Escreveu um grande número de obras, que suscitou vários estudos e interpretaçóes, os quais vão de introduções mais elementares de seu pensamento até aos estudos mais especializados. Podemos afirmar, grosso modo, que esses estudos da obra de Popper têm se dividido entre os

${ }_{1}$ Professora do Programa de Pós-Graduação em Filosofia e do Curso de Graduação em Filosofia da Universidade Federal do Pará (UFPA), Belém, PA - Brasil. (D) https://orcid.org/0000-0003-09516313. E-mail: edias@ufpa.br

https://doi.org/10.1590/0101-3173.2021.v44n3.06.p81

\section{(i)}


que se dedicam à análise de sua teoria da ciência e os que têm se voltado para sua filosofia política. Obviamente, há também os que não veem essas duas filosofias como dissociadas e que procuram mostrar as devidas relações entre ambas, além de estudos mais especializados, que procuram discutir criticamente sua filosofia, levantando problemas, apontando incongruências e aspectos obscuros, aos quais Popper sempre procurou responder quando houve oportunidade. ${ }^{2}$

O que queremos ressaltar é que a obra de Popper tem sido estudada por diversos prismas, que se traduzem em pontos de vistas diferentes e em interpretações diversas e até mesmo complementares, as quais valorizam aspectos de sua filosofia da ciência, de sua filosofia política ou de ambas. Mais recentemente, veio somar-se a esses enfoques já conhecidos uma nova hermenêutica, que procura dar destaque à dimensão ética de seus escritos (ZANOTTI, 1999, p. 230).

Kiesewetter (1997, p. 326), um dos primeiros estudiosos a investigar os fundamentos éticos da filosofia de Popper, procura mostrar as influências morais que ele recebeu e como suas convicçóes morais foram sendo moldadas desde cedo, de forma a afetar profundamente sua vida e produção filosófica. Destaca como uma situação inusitada a questão de a metodologia falseacionista ou racionalista crítica popperiana ter sido constituída muito antes de seus estudos de matemática, física e filosofia natural, na Universidade de Viena. E propóe como explicação para tal situação o fato de o método de Popper, de ensaio e erro, estar intimamente relacionado a princípios éticos.

Artigas (2001, p. 11/12) reconhece que a chave para a compreensão e a interpretação adequada da filosofia de Popper lhe foi dada por Kiesewetter, ao apontar que seu falseacionismo tem raízes éticas. E, ao tratar das questóes éticas inerentes à filosofia popperiana, desenvolve dois estudos nos quais traz à tona essa preocupação. No primeiro, evidencia o caráter ético do racionalismo crítico de Popper, de modo a diferenciá-lo do racionalismo pancrítico de seu discípulo Bartley. E, no segundo, mostra que os problemas fundamentais que o filósofo levanta têm raízes éticas que devemos levar em conta, se quisermos ter uma interpretação adequada de sua filosofia da ciência. Gattei (2009, p. 83), seguindo os passos traçados por Artigas, ao abordar o racionalismo crítico

\footnotetext{
2 Um exemplo clássico desse tipo de estudo é a obra The Philosophy de Karl Popper (1974), uma coletânea de artigos de diversos autores, que debatem aspectos relevantes da filosofia da ciência e filosofia política de Popper, aos quais ele responde, elucidando pontos obscuros ou mal-entendidos de seu pensamento.
} 
de Popper, procura salientar sua natureza ética. Sua abordagem dá destaque à decisão do filósofo pelo racionalismo como tendo por base a fé na razão. Entende ele que tal atitude racional tem como fruto uma obrigação moral e uma opção contra a violência.

Oliveira (2011, p. 22), em consonância com essa nova hermenêutica, em seu estudo Da ética à ciência, procura fornecer uma compreensão dos escritos de Popper, a partir das bases éticas de seu racionalismo critico, de sorte a superar as leituras mais tradicionais que, por não valorizarem esses fundamentos éticos inerentes a seu pensamento, não nos possibilitam uma compreensão adequada de sua filosofia como um todo. O propósito do autor é ressaltar, então, que, em Popper, "a vida, a ética e a obra estão profundamente imbricadas".

Concordamos com essa nova hermenêutica de que há uma dimensão ética na filosofia de Popper, mas nossa pretensão é olhar essa questão de uma outra perspectiva. Não pretendemos nos voltar para as raízes éticas do racionalismo crítico de Popper, tema já tratado, de resto, por vários estudiosos de sua obra, contudo, considerando que há essa dimensão ética em seu pensamento, investigar as relações entre ciência e ética, ou, mais precisamente, a natureza dessa ética, a qual está na base de sua concepção de ciência. Iremos demonstrar que a sua concepçáo de ciência se sustenta em uma ética da responsabilidade, que pressupóe a liberdade de escolha e o compromisso dos cientistas com as decisóes tomadas, uma vez que foram pautadas por certos objetivos, valores e princípios éticos, os quais eles elegeram.

Mas, é importante notar que há aspectos pouco explícitos ${ }^{3}$, bem como matizes e algumas reelaboraçóes no pensamento de Popper, quando examina a ética, no decorrer de suas obras, que possibilitam várias leituras da mesma. ${ }^{4}$

Nossa pretensão, conforme já ressaltamos, é olhar essas obras da perspectiva da ética da responsabilidade. Assim, iremos analisar apenas os escritos nos quais o filósofo apresenta, seja de uma forma ainda pouco incipiente, seja de uma maneira mais elaborada, o teor dessa ética. Tomaremos como objeto de nosso estudo, primeiramente, alguns escritos nos quais essa ética se revela ainda de forma nuançada e estreitamente relacionada à sua

\footnotetext{
3 Shearmur (1996, p. 89) manifesta a suspeita de que pode haver muito mais, nos vários escritos em que Popper trata da ética, do que ele próprio afirmou, de forma explícita.

${ }^{4}$ Niemann (2019, p. 1), por exemplo, identifica três pontos fundamentais para uma análise ética, nos escritos de Popper: um utilitarismo negativo, uma ética epistemológica e uma ética de resolução de problemas.
} 
proposta de uma lógica da investigação, sendo que, nessas obras, a questão ética diz respeito à prática dos cientistas, no âmbito das ciências teóricas ou puras. ${ }^{5}$ Dentre esses escritos, serão contemplados os seguintes: Os dois problemas fundamentais da teoria do conhecimento (1930-1933), ${ }^{6}$ o qual deu origem à sua obra clássica $A$ lógica da pesquisa científica (1934), ${ }^{7}$ objeto também de nosso estudo. Nessas obras, Popper trata da referida questão, quando propóe seu critério lógico de cientificidade, para definir a ciência empírica, isto é, a falseabilidade, complementando-o com certas regras metodológicas, que dependem da escolha dos cientistas e requer, deles, a responsabilidade por suas decisões.

Iremos, posteriormente, assinalar que a ética da responsabilidade ganha maior envergadura, quando ele trata dos compromissos dos cientistas, no âmbito das ciências aplicadas, em escritos, nos quais manifesta de uma forma mais evidente sua preocupação com as implicações éticas inerentes à ciência. Assim, serão objeto de nosso estudo os escritos: "A responsabilidade moral do cientista (1969)", ${ }^{8}$ que compóe a obra $O$ mito do contexto e "Tolerância e responsabilidade intelectual (1983)", 9 ensaio que faz parte da coletânea Em busca de um mundo melhor, nos quais Popper apresenta sua proposta de uma ética para a ciência que requer dos cientistas certas responsabilidades. Nesse sentido, o filósofo propóe uma versão renovada do juramento de Hipócrates, que expressa os compromissos éticos dos cientistas, além de certos princípios éticos que devem nortear suas pesquisas.

5 Popper (1974, p. 271-272) distingue três tipos de ciências: as teóricas ou generalizadoras, cujo interesse predominante é encontrar leis universais e submetê-las a testes. Por vezes, Popper denomina essas ciências de puras, para distingui-las das aplicadas; as históricas, voltadas para a explicação de eventos específicos, e as aplicadas, cujo foco de interesse é a predição de situações especificas. Para essas ciências, as leis universais são vistas como meios para certos fins, por isso, são tidas como estabelecidas. ${ }^{6} \mathrm{O}$ texto original escrito em alemão, Die beiden Grundprobleme der Erkenntnistheorie, é constituído de dois volumes. O primeiro foi concluído em 1932, enquanto o segundo foi desenvolvido até 1933.

7 Tal obra, publicada originalmente em alemão (Logik der Forschung), é considerada, por Popper (1972, p. 545), como uma versão abreviada do segundo volume de seus ensaios que compóem Os dois problemas fundamentais da teoria do conhecimento. E só se tornou amplamente conhecida a partir da publicação de uma versão em língua inglesa, em 1959.

${ }^{8} \mathrm{O}$ ensaio, que foi incorporado à coletânea $O$ mito do Contexto, o qual analisamos, é uma versão revisada de um texto apresentado, originalmente, por Popper, em 1968, em uma sessão especial de "Ciência e ética", no Congresso Internacional de Filosofia, realizado em Viena. A sua primeira versão foi publicada no Encounter, em março de 1969.

9 Esse artigo, que compóe a coletânea Em busca de um mundo melhor, que consultamos, é a versão de um texto apresentado em um colóquio acerca da tolerância na Universidade de Viena, em 1982 e publicado pela primeira vez em Offene Gesellschaft - offenes Universum, 1983. Uma primeira versão do mesmo foi exposta, por Popper, em uma conferência, na Universidade de Tübingen, em 1981. 


\section{Esboço de uma ética da responsabilidade na proposta de Popper de uma LÓGICA DA INVESTIGAÇÁO}

Tratar de uma ética inerente à concepção de ciência em Popper não é tarefa fácil, pois o filósofo não é muito explícito sobre o assunto, principalmente, nas obras $O s$ dois problemas fundamentais da teoria do conhecimento e A lógica da pesquisa científica, nas quais nos apresenta os grandes problemas que nortearam suas reflexões: o problema da demarcação científica e o da indução. Nos três volumes que compóem os Pós-Escritos à sua Lógica, também não há referências claras a essa questão. Poder-se-ia até mesmo questionar se, de fato, ele tem tal preocupação, na medida em que nessas obras não dedica nenhum capítulo para tratar de tal temática.

Todavia, uma análise mais atenta de suas obras nos permite vislumbrar que o tema da ética relacionado à ciência não lhe é estranho, muito embora não esteja no centro de suas análises. Em sua obra Sociedade aberta e seus inimigos, Popper (1974a, p. 246) reconhece que há uma base ética da ciência. E, na conferência "Natural Selection and the Emergence of Mind", ${ }^{10}$ comenta que "[...] o fato de a ciência não poder pronunciar-se acerca de princípios éticos tem sido interpretado como um sinal de que não há tais princípios, quando de fato a busca da verdade pressupóe a ética." (POPPER, 1993, p. 141). Essas afirmaçôes de Popper são importantes, porque nos deixam entrever que ele não ignora que ciência e ética se relacionam e que essa relação se dá por meio de valores e princípios éticos que deveriam se fazer presentes na atividade cientifica, como também, nas decisóes dos cientistas, ao assumirem certas responsabilidades por suas escolhas.

Não podemos, assim, reduzir a teoria da ciência popperiana às reflexões lógico-metodológicas, pois, se entendemos que a ciência é uma atividade norteada por valores e princípios éticos, a decisão do cientista de optar por um determinado procedimento metodológico pressupóe sempre esses valores e princípios e não apenas a pura lógica. O filósofo tinha muito bem consciência disso e deixou claro, já desde os seus primeiros escritos, que a aceitação de seu critério de demarcação científica e das regras metodológicas que ele propunha para a ciência dependiam de decisóes dos cientistas e dos objetivos e valores por eles comungados.

\footnotetext{
${ }^{10}$ Este texto foi apresentado por Popper, na primeira conferência Darwin, em 1977, no Darwin College de Cambridge, e publicado, pela primeira vez, em 1978, na revista Dialectica. Estamos utilizando aqui a versão que consta na obra Evolutionary epistemology, rationality, and the sociology of knowledge, organizada por G. Radnitzky e W. Bartley.
} 
Com efeito, nesses escritos, suas reflexóes estão mais voltadas para as ciências puras, que ele denomina de "generalizadoras ou teóricas" (POPPER, 1974a, p. 271), cujo interesse é por leis universais e em submetê-las a provas, com o objetivo de eliminar as falsas. Por isso, suas reflexóes éticas ainda não são muito evidentes. No entanto, já esboça, de uma forma nuançada, algumas preocupaçóes com um teor ético inerente à ciência, que requer a responsabilidade dos cientistas por suas escolhas, tanto por um critério de cientificidade como pela adoçáo de um procedimento metodológico.

Em sua obra A lógica da pesquisa cientifica, ao tratar do problema da demarcação científica, Popper (1972, p. 38) propóe a falseabilidade como critério definidor do caráter científico de um sistema teórico e já deixa entrever as questôes que sua aceitação envolve. É importante destacar que tal critério não é empírico e nem tampouco extraído da observação da prática dos cientistas. Trata-se de uma tese filosófica ou, mais precisamente, uma tese metacientífica, e, por isso, não pode ser considerada verdadeira ou falsa (POPPER, 2013, p. XXXIII). A aceitação ou não de tal critério deve ser encarada como fruto de uma decisão ou de uma convenção acerca de como se deve entender a atividade científica (POPPER, 1972, p. 38). Nas palavras de Popper (1972, p. 55), “[...] será sempre questão de decisão ou de convenção saber o que deve ser denominado 'ciência' e quem deve ser chamado 'cientista'."

Todavia, uma decisão dessa natureza deverá ser fruto de uma discussão racional entre partes que comungam um mesmo objetivo. E a definição desse objetivo diz respeito a uma "tomada de decisão", a qual não pode justificarse, por ultrapassar a discussão racional (POPPER, 1972, p. 39). Ora, o que Popper quer dizer é que a definição dos objetivos da ciência envolve, inequivocamente, valores e escolhas.

Os cientistas têm, portanto, que tomar uma dupla decisão: uma primeira, que se refere ao objetivo da ciência, envolvendo certos valores por eles comungados, e uma segunda, que, tendo por base o objetivo aceito, deverá discutir e chegar a um possível acordo sobre o que eles entendem por ciência e sobre seus procedimentos metodológicos.

No que diz respeito ao objetivo da ciência, Popper (2013, p. XXVII) se contrapóe àqueles que veem como seu propósito o estabelecimento de teorias absolutamente seguras ou cabalmente certas. Acredita ser a busca da verdade e, não a sua posse, o seu objetivo principal. Além de ser a meta da ciência, a verdade é um valor epistêmico primordial (POPPER, 1978, p. 24). Mas 
não é apenas um valor epistêmico, ela é também um valor ético. Salienta ele: "Creio que a verdade objetiva é um valor [...]; portanto um valor ético, talvez até um valor supremo; e a crueldade é o maior desvalor." (POPPER, 2006, p. 18). Enquanto valor epistêmico, a verdade concerne ao domínio dos fatos e regula a busca dos cientistas por teorias que correspondam a eles e, enquanto valor ético, está associada aos padrôes ou propostas a adotar. Nesse sentido, a verdade se identifica com o que é bom ou correto e orienta as discussōes na escolha de uma proposta.

Podemos sustentar que uma discussão racional, como a tomada de decisão que envolve valores éticos, foge ao campo epistêmico, uma vez que Popper deixa claro que essa questão não pode ser determinada por argumentos, por ultrapassar tal discussão. Mas isso não implica que tal escolha tenha que abdicar de todo e qualquer argumento, pois este pode ajudar de alguma maneira. Com efeito, o indivíduo, face a uma decisão moral mais abstrata, deverá analisar as consequências das diversas propostas que se apresentam, antes de fazer sua escolha. Se conseguir vislumbrar essas consequências de "forma concreta e prática", será capaz de conhecer o peso de sua decisão. Caso não consiga, estará decidindo às cegas (POPPER, 1974a, p. 240). Popper propóe, assim, uma ética que leve em conta as consequências das escolhas, o que implica em, antes de se tomar uma decisão, deve-se avaliar as consequências do que está sendo proposto e, uma vez tomada a decisão, se deverá assumir a responsabilidade moral pela opção feita.

Muito embora Popper (1974a, p. 404) advogue a distinção entre fatos e padróes, assinalando que os padróes náo podem ser reduzidos a fatos, parece que esse dualismo náo se mostra muito rígido, quando se trata da tomada de decisão acerca de sua proposta de um critério de demarcação científica e do próprio método da ciência, pois reconhece que o meio mais viável de argumentação, a favor de sua proposta, consiste em avaliar suas consequências lógicas, sua fertilidade, seu poder de elucidação dos problemas (POPPER, 1972, p. 39). A análise dessas consequências, de caráter lógico e epistêmico, apesar de não determinar as decisóes, auxiliará na escolha da proposta, já que os indivíduos podem avaliá-la, considerando certos valores, tais como correta ou incorreta, boa ou má, de sorte a decidir de forma mais consciente.

O próprio filósofo admite que, ao formular sua proposta, foi guiado por juízos de valor e predileçóes pessoais. Contudo, não requer que estas sejam aceitas incondicionalmente. Pelo contrário, solicita que se avaliem suas consequências, antes da tomada de qualquer decisão, no que tange à sua 
aceitação ou rejeição (POPPER, 1972, p. 39). No entanto, acredita ele que se trata de uma proposta aceitável para os que apreciam seu rigor lógico, como também seu intento de superação do dogmatismo, ao considerar as teorias como passíveis de crítica e, ainda, sua pretensão de unir a aplicabilidade prática com a descoberta de novas conjecturas para solucionar os problemas científicos, de modo a possibilitar o avanço do conhecimento (POPPER, 1972, p. 39).

Popper (1974b, p. 1187, nota 81) parece estar convicto de que apresentou um bom critério de cientificidade, pois, ao ser questionado por Lakatos sobre as condiçôes em que abriria mão deste, retorquiu: "Quando um outro, sendo melhor que meu metacritério, for proposto". Fica evidente que, imbuído de determinados valores e consequências, julga seu critério uma melhor alternativa face a outros, como, por exemplo, o dos positivistas. Por isso, acredita que os cientistas deveriam tomar a decisão de adotá-lo e, assim, estabelecer um acordo, por convenção, no âmbito da comunidade científica, sobre a maneira de se definir sua prática.

Entretanto, não é apenas o critério de cientificidade que pressupóe certas decisões que envolvem valores éticos. As análises das consequências e responsabilidade moral pelas escolhas feitas, bem como as regras metodológicas, propostas por Popper, para complementar o seu critério lógico, também dependem de tais decisôes. Ao se defrontar com as objeções dos convencionalistas, os quais consideravam ser possível proteger as teorias científicas contra o falseamento - introduzindo-se hipóteses ad hoc, que auxiliassem na explicaçáo das observaçóes que póem a prova a teoria, ou modificando-se o significado empírico dos conceitos que a compóem ou, ainda, eliminando-se as observaçóes que a falseiam (POPPER, 2013, p. 419/420) -, Popper procura responder a elas, recorrendo a uma metodologia, ou melhor, à regras metodológicas que definem os procedimentos que podem ser aceitos, além de certos valores que os cientistas compartilham e à própria honestidade intelectual do cientista (DIAS, 2019, p. 329).

Entende, assim, que a ciência empírica deve ser definida pelos seus métodos, isto é, pelo modo como os cientistas desenvolvem suas pesquisas e produzem as teorias científicas, ou seja, pela maneira de lidar com os sistemas científicos (POPPER, 1972, p. 52). Tendo em vista essa sua forma de conceber a ciência, Popper se preocupa em estipular as regras ou normas que deveriam orientar o cientista, em sua pesquisa. Essas regras, juntamente com o critério de demarcação, têm o caráter de convençôes e, enquanto tais, dependem de 
uma decisão que pressupóe certos valores e análise das consequências, ao adotá-las, conforme já ressaltamos.

Esse caráter convencional das regras metodológicas fica evidente, se atentarmos para a distinção que Popper faz entre "leis naturais" e "leis normativas". As leis naturais descrevem fatos que podem ou não ocorrer, de forma regular e invariável, na natureza. Nesse sentido, tais leis podem ser verdadeiras ou falsas. Ao contrário dessas primeiras, as "leis normativas" dizem respeito às normas que têm o caráter de proibiçóes ou que demandam certo modo de conduta. Visam ao estabelecimento das orientaçóes para o nosso agir, cabendo aos homens criá-las e modificá-las. Podem ser consideradas boas ou más, certas ou erradas, aceitáveis ou inaceitáveis, mas dificilmente podemos dizer que elas são verdadeiras ou falsas, pois não fazem afirmaçóes acerca de fatos. Têm o caráter de convençôes, na medida em que a decisão de obedecêlas ou mudá-las resulta do assentimento dos homens. Assim, tal decisão os torna moralmente responsáveis por elas (POPPER, 1974a, p. 75).

Contudo, esse caráter convencional das normas não significa que são arbitrárias ou que pouco importa qual ela seja. Pelo contrário, as normas podem ser aperfeiçoadas ou mesmo reputadas como melhores que outras. Isso significa dizer que é possível comparar as normas vigentes com outras que reputamos como melhores, vistas como "normas-padróes", as quais, por meio de uma decisão, foram consideradas como dignas de serem postas em prática. Mas, mesmo essas "normas-padrōes" são frutos de convençôes ou decisões dos homens, e de inteira responsabilidade de quem as adotar (POPPER, 1974a, p. 75).

As regras metodológicas, propostas por Popper para a ciência, têm natureza idêntica a essas normas-padróes, na medida em que dependem de uma decisão dos cientistas para serem aceitas, ao compará-las com outras regras de que dispóem, e julgá-las como as mais adequadas para nortear suas investigações. Tal decisão traz consigo a responsabilidade moral de respeitá-las (DIAS, 2019, p. 330).

A metodologia científica se configura, no pensamento de Popper, como uma teoria acerca dos procedimentos dos cientistas, referindo-se mais precisamente à "escolha de métodos" e às decisôes sobre como operar com os enunciados científicos (POPPER, 1972, p. 51). Nesse sentido, o filósofo propóe que os cientistas adotem regras que garantam a possibilidade das teorias cientificas serem testadas, ou seja, de serem falseadas. Essas regras 
devem pautar suas práticas, não no sentido de orientar o que exatamente eles fazem, mas de determinar o que eles devem (ought) fazer (POPPER, 1974b, p. 1036). A esse respeito, Kuhn (1979, p. 31) acertadamente comenta que há, na metodologia de Popper, vários trechos que devem ser entendidos como tentativas de prescrição de imperativos morais aos cientistas.

A metodologia popperiana se coloca, assim, no plano do "dever ser", visto que pretende indicar regras para uma prática, ou melhor, para um modo de proceder, cuja aceitação depende dos objetivos que os cientistas almejam atingir. Porém, como entender esse "dever", no âmbito dessa metodologia?

Muito embora Popper se considere um kantiano, ele não entende o dever no sentido que Kant (1980, p. 114) o concebe, em sua ética, uma vez que implica uma ação por puro respeito à lei moral. O dever se exprime, em Kant (1980, p. 120), por meio de um imperativo categórico que nos representa uma ação como necessária em si mesma, incondicionalmente. Tal imperativo ordena uma ação de maneira absoluta, como um fim em si mesma e não como meio. Assim, o dever ordenado tem caráter universal e necessário. A forma da moralidade, representada no imperativo categórico, radica no sujeito e suas motivaçóes e não propriamente no ato prescrito. Desse modo, a moralidade está, conforme nos esclarece o filósofo, na máxima da ação e não na ação mesma (KANT,1980, p. 139), ou seja, agir por dever é a maneira de dar à ação o seu valor moral.

Ao contrário de Kant, para Popper, o dever se manifesta como um meio para determinados fins. Trata-se de um dever no sentido de um imperativo hipotético (POPPER, 1974b, p. 1036), pois o mandato expresso no imperativo tem sua validez condicionada pelo fim que se deseja atingir. Fica claro, por conseguinte, que as regras metodológicas propostas visam à orientação da ação para a efetivação de um fim esperado. Isto é, dizem respeito à questão de como os cientistas devem proceder, de sorte a contribuir para o crescimento do conhecimento. Nessa linha, tal imperativo toma a seguinte forma: se os cientistas desejam contribuir para o progresso cientifico, devem proceder segundo as regras do método científico, ou seja, propondo conjecturas e submetendo-as a testes, no intuito de refutá-las (POPPER, 1974b, p. 1036).

No entanto, se os imperativos hipotéticos são condicionados por certos fins, eles têm o caráter de "preceitos práticos" e não de leis (KANT, 2016, p. 35). Desse modo, não expressam um dever necessário e universal, que constitui a moralidade, mas apenas, contingente, válido para um "gênero de 
seres racionais" graças a um acordo acerca de algumas inclinaçóes (KANT, 2016, p. 96). Na linguagem de Popper (1999, p. 51, nota 41), tais preceitos se traduziriam em recomendaçóes de caráter normativo. Ora, como entender sua afirmativa de que esse dever envolve, também, uma ética? (POPPER, 1974b, p. 1036).

Para Popper, a ética está fundada na autonomia do sujeito e na liberdade de escolha. E, muito embora considere que o princípio da autonomia kantiano está na origem de sua concepção, não é fiel a conotação dada a ele pelo filósofo prussiano, pois não entende tal autonomia como fruto de uma vontade em que o sujeito, ao escolher, as máximas escolhidas estejam incluídas, de forma simultânea, no querer como lei universal (KANT, 1980, p. 144). Popper (1982, p. 209) define o princípio da autonomia nos seguintes termos:

[...] o princípio de que náo podemos aceitar a ordem de uma autoridade, por mais elevada que seja, como base última da ética. Sempre que defrontamos uma ordem, é nossa responsabilidade julgar se ela é moral ou não. [...] Contudo, a não ser que sejamos impedidos fisicamente de fazer uma escolha, a responsabilidade será nossa. A decisão de obedecer a uma ordem, de aceitar uma autoridade, é uma decisão que nos pertence.

Toma a autonomia, nessa perspectiva, como fundamento último da ética e, enquanto tal, como oposta a quaisquer imposiçôes de uma autoridade. Independentemente desta, o sujeito é sempre capaz de discernir se o mandato, que lhe está sendo imposto, é moral ou imoral. E, seguindo sua própria consciência, decide se deve ou não aceitar tais imposições. É justamente por ser livre para decidir que a responsabilidade recai sobre suas escolhas (POPPER, 1982, p. 54). Nesse sentido, a responsabilidade é uma consequência da sua liberdade.

$\mathrm{Na}$ consciência, comenta Ferriol, dois elementos interagem para que se tome a decisão ética acertada: os princípios morais e as consequências. Seria necessário acrescentar um terceiro elemento, os valores, pois, como mostramos anteriormente, Popper deixa claro que estes também estão envolvidos na escolha, principalmente na dos cientistas. Nesse jogo interativo, a liberdade e o sentido de responsabilidade entram em ação, e a consciência se apresenta como expressão da autonomia das pessoas e, igualmente, de sua responsabilidade (FERRIOL, 2006, p. 180). O autor interpreta a ética, da perspectiva popperiana, como consequencialista, na medida em que tem em vista uma ação como moralmente correta, levando em conta suas consequências. 
Logo, partilha, com as concepçóes éticas contemporâneas, a valoração das consequências de uma ação (FERRIOL, 2006, p. 179). Todavia, acredita que tal ética pode também ser classificada como uma ética da responsabilidade, já que exige e pressupóe a responsabilidade do sujeito. Exige responsabilidade, porque não deixa que esta recaia apenas sobre uma autoridade, mas que seja compartilhada por todos. E pressupóe a responsabilidade, porque a nossa liberdade de tomar decisôes tem como consequência sermos responsáveis por elas (FERRIOL, 2006, p. 180).

No que diz respeito à ciência, a ética da responsabilidade acarreta o reconhecimento do cientista como um sujeito autônomo, a quem cabe escolher se deve ou não seguir as regras metodológicas, e a responsabilidade por tal decisão é sua. $\mathrm{O}$ fato de essas regras terem o caráter de recomendaçóes e serem condicionadas por certos fins não elimina a liberdade de escolha $\mathrm{e}$ a responsabilidade que recai sobre os cientistas, ao adotá-las. Tal ética não almeja pautar as açôes humanas de um modo universal, como pretendia Kant, mas o agir de um gênero em particular, o dos cientistas. Trata-se de uma ética aplicada à ciência, a qual toma uma ação, do ponto de vista ético, como correta, se leva em consideração as suas consequências, como também os valores e certos princípios éticos. Esses princípios se tornarão mais evidentes, quando tratarmos de obras mais recentes do filósofo.

Nesse sentido, podemos vislumbrar que, desde seus primeiros escritos, quando Popper expóe sua proposta de uma lógica da investigação científica, já esboça uma ética que exige dos cientistas responsabilidades pelas suas escolhas, em termos de definição de um critério de cientificidade, bem como em relação aos métodos adotados para nortear sua prática. Essas escolhas têm consequências para a prática da ciência, pois o cientista, ao optar pela proposta popperiana, se compromete tanto com a verdade, como valor epistêmico de primeira ordem, como com a verdade enquanto valor ético e também com certos princípios éticos, conforme Popper deixa claro, em escritos posteriores.

\section{A ética da responsabilidade nos escritos em Que Popper manifesta sua PREOCUPAÇÁO ÉTICA PARA COM A CIÊNCIA}

Nos escritos nos quais Popper se volta para questôes éticas inerentes à ciência, torna-se mais explícita a ideia de uma ética da responsabilidade dos cientistas, principalmente quanto às ciências aplicadas. 
Com efeito, em seu artigo "A responsabilidade moral do cientista", Popper sustenta que o problema da ética na ciência e da reponsabilidade dos cientistas se tornou mais amplo e evidente, devido ao desenvolvimento científico e à tendência da aplicação técnica do conhecimento produzido. Antes mesmo do advento das possíveis aplicaçóes da ciência, o "cientista puro" tinha apenas como responsabilidade a busca da verdade. Sua preocupação era somente com o aprofundamento e o avanço do assunto de seu estudo. Maxwell, por exemplo, náo teve grandes razóes para se dedicar às aplicaçóes de suas equaçóes. Porém, a situação mudou completamente, na medida em que tanto a ciência pura como todo o conhecimento acadêmico puro tendem a se tornar aplicáveis (POPPER, 1999, p. 153).

Mas o problema da responsabilidade moral do cientista, no âmbito da ciência aplicada, não é novo. Remonta ele aos gregos, mais especificamente a Hipócrates, que propôs um juramento - conhecido como "Juramento de Hipócrates" - no qual define obrigaçôes e deveres para a prática da arte médica.

Os compromissos expressos nesse juramento exerceram grande influência na cultura ocidental, ao se constituírem no código de ética dos médicos e de profissionais de várias outras áreas (CAIRUS; RIBEIRO JUNIOR, 2005, p. 151). A ética, presente no juramento de Hipócrates, tem sido entendida, por alguns, como uma espécie de etiqueta, uma pequena ética, a respeito de um conjunto de regras referentes ao comportamento em sociedade. Nesse sentido, afirmam esses autores que os escritos hipocráticos trazem “[...] um conjunto de recomendaçóes relacionadas com a etiqueta médica e, ainda, mais especificamente, com o decoro médico" (CAIRUS; RIBEIRO JUNIOR, 2005 , p. 148). Desse modo, as "regras de etiqueta" visavam à orientação do comportamento dos médicos, no exercício de sua prática, de tal modo que sua arte fosse reconhecida pela sociedade e se tornasse possível diferenciar o bom médico do charlatão (CAIRUS; RIBEIRO JUNIOR, 2005, p. 148).

Para Popper (1999, p. 156), o juramento de Hipócrates foi mal interpretado, ao ser visto como uma espécie de "moral de corporação" ou como uma espécie de etiqueta, para reger o exercício da profissão. No seu entender, tal juramento "[...] não era um juramento de licenciatura, mas um juramento a ser feito pelo aprendiz da profissão médica. Essencialmente, faziase no início da primeira iniciação do estudante à ciência aplicada." (POPPER, 1999, p. 154). Trata-se, assim, de uma ética aplicada à arte médica, que, por meio de alguns preceitos, pretende comprometer o iniciado com certos valores e princípios éticos para o exercício de sua prática. Todavia, embora tal 
juramento esteja vinculado à prática da medicina, em suas reflexóes, Popper procura atualizá-lo de sorte a trazer a questão ética para o campo de todas as ciências e, em particular, para o âmbito das ciências aplicadas.

Esse juramento é composto de três partes principais: uma primeira, que constitui uma invocação, dirigida aos deuses protetores da arte médica; uma segunda, as cláusulas, que dizem respeito aos compromissos médicos, sendo estes de dois tipos: um referente ao "pacto familiar e corporativo" e outro, quanto aos padróes de conduta pessoal para o exercício da arte médica; a terceira parte, a qual é uma imprecação, lembra a punição a que estão sujeitos os que violam o juramento (CAIRUS; RIBEIRO JUNIOR, 2005, p. 153).

Popper (1999, p. 154) se refere apenas às cláusulas que expressam os compromissos do aprendiz. Dentre eles, destaca três: um primeiro, no qual ele deve reconhecer sua obrigação para com o mestre; um segundo, em que o aprendiz se compromete a dar continuidade à tradiçáo de sua prática, a manter seus padrôes elevados, considerando a ideia de santidade da vida, bem como repassar esses padróes aos novos aprendizes. Esses dois primeiros compromissos, assinalados pelo filósofo, concernem, de certa forma, ao "pacto familiar", que Cairus e Ribeiro Junior pontuam, já que o mestre, muitas vezes, era o próprio pai, situação comum na antiguidade grega, porque os conhecimentos práticos, como a arte médica, eram transmitidos no próprio seio da família. E o terceiro se relaciona à conduta do médico, ao se comprometer em ajudar aos que sofrem e guardar silêncio a propósito do que viesse a tomar conhecimento, no exercício de sua arte.

A pretensão de Popper, ao produzir uma versão atualizada do juramento de Hipócrates, é suscitar novas reflexões sobre problemas éticos, os quais envolvem a ciência, principalmente sobre aqueles que dizem respeito às responsabilidades dos cientistas. Assim, tendo por base tal juramento, propóe ele uma espécie de "juramento do cientista responsável", de modo a deixar claras suas responsabilidades (SOLANO, 2005, p. 288). Para tanto, define três compromissos dos cientistas, que se traduzem em deveres e pressupóem certos princípios éticos: um primeiro, relacionado à sua responsabilidade profissional, estabelece como dever do cientista e do próprio aluno, enquanto aprendiz de uma ciência, contribuir para o crescimento do conhecimento, como também se engajar na busca da verdade ou de uma melhor aproximação da verdade, tendo em vista sempre a falibilidade humana, ou seja, que podemos, eventualmente, cometer erros. 
Mas tal fato não deve servir de pretexto, para que se negligenciem os erros ou, mesmo, para que se seja complacente para com eles. O cientista deve sempre perseguir o mais alto padrão para julgamento do seu trabalho, além de ter o dever de ampliar esses padróes. Ao propor esse compromisso, Popper (1999, p. 155) procura deixar clara a relação entre o trabalho intelectual e a ética, principalmente no que concerne à ciência aplicada, pois o cientista empenhado na busca da verdade deve ter sempre por princípio a admissão da falibilidade e a limitaçáo do conhecimento, ou seja, que nosso conhecimento é limitado e falível e que nossa ignorância é ilimitada. Quando o cientista não tem consciência desses limites, acaba por assumir uma atitude arrogante, ao pensar que possui a verdade.-

O segundo compromisso se refere ao aluno, enquanto aprendiz de uma ciência, mas se aplica também aos cientistas. Requer que os alunos e os cientistas sejam seguidores de uma tradição de debate e de crítica, ao participarem de uma comunidade intersubjetiva, que segue esse padrão. Os alunos, enquanto parte dessas instâncias, devem ter uma atitude de respeito para com todos os que deram a sua contribuição para a busca da verdade, como também devem ser leais a seus mestres que compartilharam com eles seus conhecimentos. Contudo, isso não significa que devem ser meros recebedores do que lhes é repassado, pelo contrário, enquanto seguidores de uma tradição crítica, têm o dever de manter uma atitude crítica face ao que é produzido pelos outros, inclusive pelos seus mestres, colegas e por eles mesmos.

Vale lembrar, ainda, que o cientista e iniciados têm o dever de se precaver para que não venham a assumir atitudes arrogantes ou, mesmo, se deixar levar por certas modas intelectuais (POPPER, 1999, p. 155). Uma dessas modas, a qual Popper (2006, p. 173) combate, é o estilo obscuro, das palavras grandiloquentes e incompreensíveis, que muitas vezes é motivo de orgulho e visto como fruto de profundidade. Assim, é dever do cientista uma de suas maiores responsabilidades, pois está relacionada com a própria subsistência da sociedade aberta e da democracia - utilizar uma linguagem simples e clara, a fim de expressar os conhecimentos produzidos, de maneira torná-los acessíveis aos iniciados. Desse modo, deve "[...] reduzir o jargão científico ao mínimo - o jargão de que muitos nos orgulhamos, quase como se de um brasão ou sotaque de Oxford se tratasse." (POPPER, 1999, p. 140).

O terceiro compromisso diz respeito à lealdade suprema. Trata-se da responsabilidade moral do cientista para com a humanidade. Ou seja, seu compromisso maior deve ser com a humanidade, por isso, precisa ter 
consciência das consequências da aplicação dos resultados de suas pesquisas, pois estes podem afetar a vida de muitas pessoas, não só para o bem, como também para o mal. Assim, sua atitude ética deverá ser "[...] tentar prever e acautelar-se contra qualquer possível perigo ou uso indevido dos seus resultados, mesmo que não deseje que estes resultados sejam aplicados." (POPPER, 1999, p. 156). A pretensão de Popper (1999, p. 157) é que os cientistas, como as políticas públicas, estejam comprometidos com o alívio do sofrimento evitável.

Nesse Juramento de Hipócrates, por assim dizer renovado, o qual traduz as responsabilidades dos cientistas, ao escolherem uma determinada forma de praticar a ciência, estão pressupostos alguns valores e certos princípios éticos que os cientistas devem levar em conta, em sua prática. $\mathrm{O}$ valor epistêmico e ético supremo é a verdade. Nesse sentido, os cientistas são buscadores da verdade, sendo esta entendida tanto como expressão do que é verdadeiro como do que é bom e correto, ou melhor, do próprio bem. E os princípios éticos, que lhes possibilitam a busca consciente da verdade, são a falibilidade, a discussão sensata e a aproximação da verdade.

Em sua conferência “Tolerância e responsabilidade intelectual”, Popper (2006, p. 180) explicita que tais princípios, subjacentes à discussão racional, são ao mesmo tempo epistemológicos e éticos. $\mathrm{O}$ primeiro princípio, o da falibilidade, implica o aceite do fato de que podemos errar e que nossos erros são instrutivos, porque indicam que, em uma discussão crítica, talvez um esteja errado e o outro certo ou, então, é possível que ambos estejam errados (POPPER, 2006, p. 180). Desse modo, a ideia de erro conduz à ideia de verdade como um ideal, que talvez não possa ser atingido, pois, muito embora os cientistas busquem a verdade, nunca poderáo estar convictos de que a encontraram, dada a possibilidade de erro. O segundo princípio, o da discussão sensata, requer que se apresentem razóes a favor ou contra uma teoria que está sendo objeto de crítica (POPPER, 2006, p. 180). A escolha por uma determinada teoria será considerada sensata, se ela se sustentar em bons argumentos e se resistir aos argumentos críticos que tentam falseá-la (POPPER, 1987, p. 87). E o terceiro, o da aproximaçáo da verdade, preconiza que, por meio da discussão crítica, é possível nos aproximarmos da verdade e, dessa forma, a um melhor entendimento do assunto, mesmo quando não é possível um acordo (POPPER, 2006, p. 180).

Esses princípios éticos levam à ideia de tolerância recíproca entre mestre e iniciados. Em outras palavras, os que desejam conhecer algo, como 
os iniciados em uma ciência, que querem aprender com seus mestres, devem tolerá-lo, e têm igual direito de serem tolerados. A tolerância advém do fato de que todos são seres falíveis e que o conhecimento é, em princípio, limitado. Disso decorre a possibilidade do erro, na busca da verdade.

Popper reconhece que, em matéria de conhecimento, não há autoridades, já que todas as teorias são susceptíveis de crítica: até mesmo a melhor testada pode esconder erros crassos. Assim, é tarefa do cientista identificar não apenas seus erros, através da autocrítica, como também de seus colegas, para que o conhecimento progrida, razáo pela qual a atitude tolerante se mostra importante para a discussão critica de teorias, de modo a tornar possível o avanço do conhecimento.

\section{CONSIDERAÇÓES FINAIS}

Procuramos demonstrar que, na teoria da ciência de Popper, há certas preocupaçóes com as relaçóes entre ciência e ética, traduzidas em uma ética da responsabilidade dos cientistas, na qual estão pressupostos a liberdade de escolha, valores e princípios éticos. Essas preocupaçôes se apresentam já desde suas primeiras obras, quando define um critério de cientificidade e o complementa com uma metodologia. Fica evidente, então, que a aceitação desse "padrão" de pesquisa é fruto de uma escolha dos cientistas. Com base nos objetivos que têm em vista, como também em certos valores e princípios éticos, eles decidem pela adoção ou não desses padrôes, para nortear sua prática. $\mathrm{O}$ que torna a decisão ética é a liberdade de escolha e a consequente responsabilidade por tal decisão. Em escritos posteriores, o filósofo procura aprofundar suas reflexóes em termos de uma ética para a ciência, ao propor certas responsabilidades para os cientistas, inspiradas no Juramento de Hipócrates.

Tais responsabilidades têm como pressupostos determinados valores, como a verdade (valor epistêmico e ético), e certos princípios éticos: falibilidade, discussão sensata e aproximação da verdade. Mas, acima de tudo, é a autonomia do cientista, sua liberdade de escolha, que o torna responsável por suas decisôes. Assim, diante das várias situaçóes, muitas vezes difíceis, as quais se apresentam aos cientistas, com relaçáo ao direcionamento de suas pesquisas e às aplicaçóes técnicas, cabe somente a eles avaliar e decidir. Ninguém pode dar-lhes conselhos ou assumir o peso de suas responsabilidades. O que os torna responsáveis por suas escolhas é o fato de eles poderem entrever as implicaçóes 
de suas descobertas. São os únicos capazes de prever, por exemplo, os perigos do lixo atômico ou do uso de transgênicos. Desse modo, a produção do conhecimento gera a responsabilidade pelo mesmo, e nenhum cientista pode se isentar dela. Nessa perspectiva, suas responsabilidades são muito maiores do que supóem, pois envolvem o futuro da própria humanidade, na medida que recaem sobre ela tanto as boas consequências como as más, em virtude das aplicaçóes técnicas da ciência.

Popper, em sua ética da responsabilidade, na medida em que considera que os cientistas devem ter lealdade suprema para com a humanidade e elege a verdade como valor ético superior, responsabiliza o cientista pelo bem da humanidade, pois sua decisão está pautada por esse valor. Assim, o cientista, ao decidir, não deve esquecer que sua responsabilidade maior é com a humanidade e que deve priorizar o alívio do sofrimento e cultivar atitudes que tornem o mal evitável. Esse dever para com a humanidade, presente na ideia de reponsabilidade, dá à sua ética um novo caráter, visto que não restringe o âmbito da moralidade a um ato presente, no qual o direito do outro tem que ser respeitado, mas há uma projeção para o futuro, uma ve que o cientista tem que se preocupar com o mal evitável e com o que os resultados das aplicaçóes técnicas da ciência podem causar para a humanidade.

As reflexôes de Popper deixam entrever, portanto, suas preocupaçóes com as aplicaçóes práticas da ciência e, muito embora expresse, em alguns de seus escritos, que suas análises não têm como foco central os perigos da guerra nuclear, tal tema se faz presente em suas reflexóes, quando aborda questóes mais amplas relacionadas a um ethos para a ciência, as quais trazem à tona temas relevantes e bastante atuais, concernentes à tecnociência. A posição que defende, em termos de uma ética da responsabilidade para os cientistas, antecipa alguns aspectos das análises que serâo feitas, posteriormente, por outros filósofos dedicados à investigação das questóes éticas relativas à ciência e à tecnologia, como Hans Jones, que se voltou para os problemas éticos associados à tecnologia e à defesa da ideia de uma ética da responsabilidade como norteadora do progresso científico e tecnológico. 
DIAS, E. A. Science and ethics in Popper: the ethics of scientists responsibility. Trans/ form/ação, Marília, v. 44, n. 3, p. 81-100, Jul./Set., 2021.

\begin{abstract}
The present paper aims to analyze the relationship between science and ethics in Popper, more precisely, the nature of that ethics that is at the base of his theory of science. Our intention is to show that their conception of science is founded and an ethics of responsibility, which presupposes the autonomy of scientists, their freedom of choice, which makes them responsible for their decisions by certain research "standards". We will show that this ethics of responsibility is already present in its research logic, in a less explicit way, when his concerns are focused on the problem of scientific demarcation and his proposal for a criterion of scientificity and a methodology for science. The adoption of such a proposal requires scientists to make a decision that involves goals and values. In writings, in which he expresses his concerns about ethical issues inherent in science, this ethics of responsibility is clearly presented when defining certain commitments for scientists based on the Hippocratic oath, as well as the ethical principles that should guide their research.
\end{abstract}

Keywords: Science. Ethics. Values. Autonomy. Responsibility

\title{
REFERÊNCIAS
}

ARTIGAS, M. Lógica y Ética en Karl Popper. Navarra/España: EUNSA, 2001.

CAIRUS, H. F.; RIBEIRO JR,W. A. Textos hipocráticos: o doente, o médico e a doença. Rio de Janeiro: Fiocruz, 2005 (Coleção História e Saúde).

DIAS, E. A. A ciência como um jogo em Popper. Revista Griot. Amargosa - BA, v. 19, n. 3, p. 327-337, out. 2019.

FERRIOL, A. M. Ética médica como ética aplicada em perspectiva popperiana. In: CONGRÉS VALENCIA DE FILOSOFIA, XVI. Valencia, Facultat de Filosofia i Ciéncies de l'Educación, 6,7 i 8 d'abr. 2006. Valencia: Universitat de Valencia, 2006, p. 179-189. Disponível em http://roderic.uv.es/handle/10550/46973. Acesso em: 10 jn. 2020.

GATTEI, S. Karl Popper's philosophy of science: rationality without foundations. New York/London: Routledge Studies in the Philosophy of Science, 2009.

KANT, I. Fundamentaçáo da metafísica dos costumes. In: Textos selecionados. São Paulo: Abril Cultural, 1980.

KANT, I. Crítica da razáo prática. Petrópolis/R.J.: Vozes; Bragança Paulista/S.P.: Editora Universitária São Francisco, 2016.

KUHN, T. Lógica da descoberta ou psicologia da pesquisa. In: LAKATOS, I.; MUSGRAVE, A. A crítica e o desenvolvimento do conhecimento. São Paulo: Cultrix/ Editora da Universidade de São Paulo, 1979. p. 5-31. 
NIEMANN, H. J. Karl Popper's Three Methods of Theoretical Ethics. Improved and extended version of NIEMANN, H. J. Karl Poppers drei theoretische Ethiken. In: FRANCO, G. (ed.). Handbuch Karl Popper. Wiesbaden: Springer, VS 2019. p. 553-573. Disponível em: https://www.researchgate.net/publication/339796771_Karl_ Popper's_Three_Methods_of_Theoretical_Ethics. Acesso em: 03 set. 2020.

OLIVEIRA, P. E. de. Da Ética à ciência: uma nova leitura de Karl Popper. São Paulo: Paulus, 2011.

POPPER, K. A lógica da pesquisa científica. São Paulo: Cultrix, 1972.

POPPER, K. A sociedade aberta e seus inimigos. v. II. Belo Horizonte: Itatiaia; São Paulo: Editora da Universidade de São Paulo, 1974a.

POPPER, K. Replies to my Critics: Reply to Medawar on Hypothesis and Imagination. In: SCHILPP, P. A. (ed.). The Philosophy of Karl Popper. v. II. La Salle, Illinois: Open Court, 1974b. p. 1030-1037.

POPPER, K. Lógica das ciências sociais. Rio de janeiro: Tempo Brasileiro; Brasília: Editora da Universidade de Brasília, 1978.

POPPER, K. Conjecturas e refutaçóes. Brasília: Editora da Universidade de Brasília, 1982.

POPPER, K. O realismo e o objetivo da ciência. Lisboa: Dom Quixote, 1987.

POPPER, K. The Natural Selection and the Emergence of Mind. In: RADNITZKY, G.; BARTLEY, W.W. III (ed.). Evolutionary Epistemology, Racionality, and the Sociology of Knowledge. La Sale, Illinois: The Open Court, 1993. p. 139-155.

POPPER, K. O mito do contexto: em defesa da ciência e da racionalidade. Lisboa: Ediçôes 70, 1999.

POPPER, K. Em busca de um mundo melhor. São Paulo: Martins Fontes, 2006.

POPPER, K. Os dois problemas fundamentais da teoria do conhecimento. São Paulo: Editora Unesp, 2013.

SCHILPP, P. A. (ed.). The Philosophy of Karl Popper. v. I e II. La Salle, Illinois: The Open Court, 1974b.

SHEARMUR, J. The political Thought of Karl Popper. London and New York: Routledge, 1996.

SOLANO, J. F. M. El problema de la verdade em K. Popper: reconstrucción históricosistemática. A Coruńa: Netbiblo, 2005.

ZANOTTI, G. Karl Popper: antes y después de Kyoto. Revista Arbor, p. 229-243, jun. 1999.

Recebido: 16/6/2019

Aceito: $13 / 8 / 2020$ 